Rodolfo Piskorski

Universidade Federal de Santa Catarina

\title{
Círculos viciosos: intersecções de gênero e espécie em A Fonte da Vida, de Darren Aronofsky
}

Resumo: O filme de Darren Aronofsky, A Fonte da Vida (The Fountain, 2006), se oferece a uma leitura produtiva das formas em que discursos de opressão se interseccionam ao serem codificados cinemática e/ou ideologicamente. Este artigo analisa as diferenças de gênero, espécie e raça/etnia no filme e o modo em que são constitutivamente articuladas para possibilitar a "imanência" do Outro em cada um desses discursos, produzindo assim o sujeito "transcendental". Parto de uma compreensão filosófica do papel essencial da diferença de espécie (e do privilégio do status do humano) na constituição interseccional de outros vetores de diferença, como o gênero, o sexo, a raça e a etnia. Articulo, enfim, esse modo amplo de abordagem interseccional com uma discussão da relação com a morte que é supostamente exclusivamente humana e que permite que a humanidade seja construída como oposta à animalidade.

Palavras-chave: Teoria Interseccional; animalidade; Pós-Humanismo; cinema.

Copyright (c) 2013 by Revista Estudos Feministas.

${ }^{1}$ Trinna GRILLO, 1995, p. 18.

2 Maneesha DECHKA, 2008, p. 249.

\section{Introdução}

A Teoria Interseccional surgiu na área do Direito como tentativa de compreender a opressão e a injustiça que não se configurassem de acordo com identidades raciais e/ou de gênero estáveis.' Seu foco na natureza interseccional das fontes da opressão procurava lidar com os problemas das políticas públicas que, ao aderirem a políticas identitárias, não alcançavam os indivíduos que mais precisavam de assistência - exatamente aqueles que estavam mais vulneráveis às múltiplas formas de injustiça e que não vinham à tona nos esquemas de identidades estáveis do desenvolvedores de políticas. Além das mudanças radicais exigidas das práticas governamentais pela Teoria Interseccional, esta foi adotada e absorvida como uma ferramenta crucial em teoria crítica e na crítica feminista. $^{2}$ 
${ }^{3}$ DECHKA, 2008, p. 251.

${ }^{4}$ Cf. Laura MULVEY, 1983; Ann KAPLAN, 1997; Teresa de LAURETIS 1994.

\footnotetext{
5 "'Therefore, the Lord God banished Adam and Eve from the Garden of Eden and placed a flaming sword to protect the tree of life' - Genesis 3:24" ('Assim, Senhor Deus baniu Adão e Eva do Jardim do Éden e colocou uma espada flamejante para protege a árvore da vida' - Gênesis 3:24"). (THE FOUNTAIN, 2006, tradução minha).
}

Estou interessado, porém, no potencial disponível na Teoria Interseccional para se ler textos - literários, fílmicos e outros - como produtos e produtores de ideologia. Apesar de sua origem no Direito e de seu compromisso invejável de fazer da teoria algo aplicável, essa teoria oferece ferramentas importantes para a teoria e a crítica literária e cultural, mesmo que isso represente um passo "para trás" em direção ao que a Teoria Interseccional chamaria talvez de uma dimensão "apenas" textual e teórica. Arrisco-me nesse "retorno ao texto" na tentativa de demonstrar quão produtiva a Teoria Interseccional pode provar ser quando precisamos ler intersecções de discursos de alteridade que possam ainda parecer novos e difíceis de apontar. Refiro-me às conexões complexas e por vezes polêmicas entre a marca da espécie e as outras marcas de diferença "tradicionais". Se, como explora Deckha, pode-se facilmente contestar a inclusão da categoria de espécie na análise interseccional, ${ }^{3}$ talvez um retorno ao texto seja exatamente o que é preciso para demonstrar como todas as marcas de diferença estão, de fato, interrelacionadas com a exploração animal. Assim como a crítica feminista no passado se voltou para textos fílmicos e como eles constroem subjetividades, para mostrar a difusão do discurso da diferença sexual ${ }^{4}$ - e a importância e o escopo de criticá-la -, a crítica pós-humanista da superioridade humana tem muito a ganhar ao expor como os textos articulam múltiplos discursos de diferença com o especismo para ativálos e potencializá-los. Como tentarei demonstrar em minha análise do filme A Fonte da Vida (The Fountain, dirigido por Darren Aronofsky e lançado em 2006), não é possível ler a fundo o discurso de gênero e colonização do filme sobre transcendência e imanência sem sublinhar sua dependência ao discurso de espécie que ele tenta ocultar.

\section{A diferença de gênero e as três linhas narrativas em $A$ Fonte da Vida}

Pode-se provar facilmente que o filme se organiza ao redor do binômio masculino-feminino e enfatiza a importância estrutural dessa dicotomia através da epígrafe sobre Adão e Eva, retirada do Gênesis, ${ }^{5}$ e da estrutura fragmentada de seu enredo. Ao dividir seu enredo em três linhas narrativas que focam a diferença de gênero, o filme tenta estabelecer o par homem-mulher como a fundamentação natural e atemporal para a discussão de seus temas: a morte, a (i)mortalidade, a transcendência e o amor.

A principal linha narrativa (que chamo aqui de "Presente") se passa em uma cidade anônima da América do Norte, onde o cientista Tommy (Hugh Jackman) tenta lidar com a doença de sua esposa, Izzy (Rachel Weisz). Ela está 
escrevendo um livro, passado na Espanha quinhentista e intitulado "The Fountain" (A Fonte), que acaba sendo a segunda linha narrativa (adiante referida como "Espanha"). Em sua história, a rainha espanhola Isabel (também Rachel Weisz) envia um de seus melhores soldados, Tomás (Jackman), junto com uma pequena trupe, para a América Central, para que encontrem a Árvore da Vida bíblica. Esses dois enredos são cruzados com um terceiro, menos narrativo, que chamo de "Espaço", em que Tommy habita uma grande esfera de vidro, supostamente no futuro remoto, que está vagando pelo espaço. No centro da esfera, há uma árvore antiga com a qual ele fala com carinho e, enquanto olha para as estrelas acima da esfera, assegura a árvore que ela sobreviverá.

Apesar de a narrativa do Presente ser a principal, o filme inicia explorando a riqueza imagética dos enredos da Espanha e do Espaço com uma trama frouxa. Somos apresentados a uma sequência de cenas de suspense e ação, que inclui batalhas entre os colonizadores espanhóis e os ameríndios, para depois sermos surpreendidos pelas cenas lentas e silenciosas no Espaço, que são habitadas tão somente pelos minuciosos rituais do protagonista. O motivo do círculo emerge continuadamente em ambas as narrativas, na forma de anéis, cápsulas de vidro, padrões em ladrilhos, estrelas, tatuagens e a própria esfera transparente do setting do Espaço. Num momento no qual o protagonista se dirige à árvore, aparentemente lembrando-se de sua companheira real, lzzy aparece ao seu lado dentro da esfera, e, por meio de suas lembranças, somos levados ao Presente e à primeira cena que é, de fato, narrativa, a qual será de crucial importância para amarrar as pontas das outras tramas.

Izzy aparece no limiar da porta do escritório de Tommy, insistindo para que saiam para caminhar e admirar a primeira nevada. Ele rejeita a sugestão, alegando muito trabalho, e ela parte visivelmente frustrada. Ele se levanta para segui-la, chamando-a pelo nome, mas é interrompido por um colega que lhe pede com urgência para ir até o centro cirúrgico, e então temos uma tomada de lzzy saindo por portas duplas em direção a uma luz forte, na qual sua figura vestida de branco se dilui. Apresentado dessa maneira, o enredo do filme se encontra emoldurado por um clássico drama doméstico de casais, em que a mulher deseja que passem mais tempo juntos, enquanto o homem só vê a importância de continuar trabalhando. A tomada subjetiva de Tommy observando Izzy sair em direção à rua (enquanto sua silhueta se perde contra a luz) importa na medida em que marca a mulher como imanente, como se confundindo-se com seu ambiente, e se tornará ainda mais crucial mais adiante, quando a própria luz se tornar um dos motivos visuais do filme. 
Gradualmente compreendemos a relevância para os personagens desse conflito rápido quando descobrimos por que é importante para Tommy trabalhar e para Izzy passar mais tempo com ele: Tommy é um cientista que pesquisa tumores no cérebro de macacos e, uma vez que sua esposa sofre do mesmo mal, ele acredita ser capaz de ajudá-la se trabalhar incansavelmente em uma possível cura. Ela, por outro lado, sente que a morte se aproxima e que talvez seja mais importante que eles estejam juntos nessa última fase.

Esse conflito matrimonial, aparentemente simples em relação à administração do tempo, é posicionado no centro do filme na forma de seu conflito central: duas posturas relativas à iminência da morte, ambas equacionadas com a diferença de gênero. Enquanto Tommy assume o papel "masculino" do explorador que penetra os crânios de macacos para adiar o Outro incognoscível - a morte -, Izzy adota o papel mais "feminino" de encontrar na morte um tipo de graça e sublimidade, aprendendo a lidar com algo crescendo no seu corpo como um tipo cruel de gravidez inversa e mortífera. Essa dualidade já é estabelecida desde o início do filme pela citação da Bíblia. A Queda edênica marca o início da condição humana como a conhecemos, sendo a inevitabilidade da morte a principal diferença entre a vida dentro e fora do Paraíso; mas a citação marca a condição humana a mortalidade - como uma condição que é essencialmente projetada sobre um casal (heterossexual). A consequência disso é que a principal questão do filme se resume à necessidade de aprendermos a elucidar os mistérios da união heterossexual e das diferenças entre os sexos para compreendermos os mistérios da mortalidade humana.

Em sua tentativa de universalizar esse conflito, transplantando-o para o passado e para o futuro, o filme acaba expondo não só a forma pela qual o drama da mortalidade e o desejo por transcendência são atravessados pela diferença de gênero, mas também que o discurso de gênero depende das outras diferenças que o possibilitam, ao mesmo tempo que as produz. Assim, a narrativa da Espanha intercala a questão da imortalidade (que, para o filme, é uma questão de gênero) tanto com práticas coloniais quanto com a exploração ocidental da natureza. Por sua vez, o Presente mostra como o conflito de gênero entre Tommy e lzzy depende de uma certa manipulação, considerada apropriada, dos corpos animais no laboratório. Por fim, o Espaço traduz essa lógica de dominação para a viagem espacial hiperbólica. Mas, acima de tudo, uma análise mais cuidadosa pode mostrar como Tommy e lzzy, apesar de separados em suas posturas binariamente gendradas, estão reproduzindo a mesma lógica de opressão. Nas seções seguintes, exploro como o discurso da diferença de gênero acaba se enredando

1062 Estudos Feministas, Florianópolis, 21 (3): 1059-1080, setembro-dezembro/2013 
- Tomás descreve o inquisidor como "um inimigo vicejando dentro das fronteiras dela [a Espanha], regalando-se em sua força" ("an enemy thriving within her borders, feasting on her strength"), e a rainha pronuncia que "a fera corre solta em meu reino. [...] E agora ele afia suas garras para mais uma estocada fatal. Minha salvação jaz nas selvas da Nova Espanha" ("the beast runs amok in my kingdom. [...] And now he's sharpening his talons for one more fateful push. My salvation lies in the jungles of New Spain") (THE FOUNTAIN, 2006, tradução minha).

7 As intersecções entre discursos de gênero e de colonização foram muito bem lidas pelos estudos feministas, mas o espaço limitado não me permite revisar essa literatura.

8 Paul BROWN, 2000, p. 206 tradução minha.

${ }^{9}$ BROWN, 2000, p. 207. com outras ideologias dentro das múltiplas narrativas do filme A Fonte da Vida.

\section{Gênero e colonialismo na narrativa da Espanha}

Na Espanha somos apresentados basicamente a uma transcrição do conflito do Presente, movimento que supostamente fortalece sua validade, e a muitos elementos da trama que nos ajudarão a compreender o restante da narrativa do filme. Isabel, a rainha espanhola, está buscando a imortalidade na Terra, em sua tentativa de encontrar a Árvore da Vida edênica, e é acusada de heresia pelo principal inquisidor espanhol, que, à medida que consegue condenar mais aliados da rainha como hereges, tomando suas terras no processo, aos poucos toma o controle do território espanhol.

O conflito entre as posturas masculina e feminina perante a morte é reinscrito na narrativa espanhola na medida em que o poder crescente do inquisidor é equacionado a uma doença degenerativa. ${ }^{6}$ Dessa forma, a primeira reação de Tomás em resposta a esse câncer inquisitorial é assassinar o inquisidor com uma flechada, mas ele é impedido na última hora por outro soldado da rainha, que lhe informa que ela não vê na morte do inquisidor a solução. O plano dela é enviar Tomás para a América Central, onde ela crê que a Árvore da Vida foi encontrada por um padre, para trazer-lhe provas de vida imortal. Assim como o cientista no Presente, Tomás deseja matar o "câncer" que devora o "reino" de Isabel, enquanto ela deseja uma relação mística com a morte para vencê-la.

Não só o filme traduz seu conflito de gênero do Presente para a Espanha do século XVI, mas o discurso colonial inerente a essa busca na América Central já foi provado ser profundamente assentado sobre uma lógica de gênero." Como apontado por Paul Brown, "toda a empreitada [colonial], travada no campo da ordem psíquica, da coesão social, do destino nacional, da missão teológica, da redenção do pecador e da conversão do pagão é conduzida em relação ao corpo feminino". ${ }^{8}$ Brown demonstra como as práticas coloniais constroem tanto os povos colonizados quanto os territórios ocupados como femininos, e, assim, disponíveis para serem controlados e penetrados, assim como legitimam seus objetivos por meio de um discurso de civilidade que se encontra ligado à ideia de uma pureza feminina. ${ }^{9}$

A narrativa da Espanha em A Fonte da Vida também acaba utilizando o discurso colonial para impulsionar sua narrativa da diferença de gênero, ou, pode-se dizer também, o componente de gênero é cooptado como legitimação para 
${ }^{10}$ Ania LOOMBA, 2000, p. 328

"BROWN, 2000, p. 207, tradução minha. a empreitada colonial. A territorialidade que está em jogo no enredo da Espanha é, em última análise, uma questão de políica sexual. $O$ inquisidor afirma que deseja que a rainha seja enforcada como uma bruxa, enquanto demarca em um mapa mais uma parte da Espanha que ele passou a controlar por meio de seus processos inquisitoriais. Por outro lado, Tomás se dirige à rainha como se ela fosse uma deusa, estabelecendo assim o outro polo da dualidade entre virgem e prostituta, que se encontra em funcionamento na imagética católica. ${ }^{10}$

Se a expansão territorial do inquisidor sobre a Espanha (que é chamada de she, "ela") adquire sentido em relação às heresias de Isabel, a invasão da América Central exercida por Tomás se dá para que a rainha e seu reino possam ser salvos da corrupção que o inquisidor representa: Tomás vê a expansão do inquisidor na Espanha como nada além de uma tentativa de estupro de sua rainha e de sua pátria-mãe, e é a sua validação para conquistar a América Central.

É importante nesse momento sublinhar que a missão de Tomás não se limita a uma proteção sacra de uma rainha virginal. Como Brown demonstra, o colonizador John Rolfe, em carta a seu governador, precisa estabelecer com firmeza que sua vontade de se casar com Pocahontas - apesar de não ser fruto de luxúria, mas de um desejo colonizador -, leva em conta a importância da união sexual com ela para que assim eles cumpram a missão pia de constituir família e "trabaIhar nos vinhedos do Senhor". " A colonização, portanto, não só é levada a cabo na forma de uma política dos desejos sexuais dos nativos e das mulheres brancas, mas é também uma ferramenta fundamental para reforçar a heteronormatividade, ou, como enfatizei acima, esse mecanismo funciona por duas vias - a família heterossexual e suas funções na civilização capitalista servem também para validar a colonização.

Assim, é de relevância crucial que o par homemmulher, que argumentei estar impregnado na estrutura do filme, reemerja na relação entre uma rainha e o seu conquistador. Isabel pede para Tomás se ajoelhar perante ela e, inscritos no círculo desenhado pelos ladrinhos, ela lhe dá uma aliança representando a promessa dele de salvar a Espanha e o compromisso dela de ser sua Eva, caso ele encontre o Éden. Ela lhe promete que, se ele encontrar a Ávvore da Vida, "juntos [eles] viverão para sempre", reforçando a suposição heterossexista de que a questão da mortalidade humana e do mistério da morte depende da revisitação da união edênica entre homem e mulher, um vínculo tomado como a configuração natural e necessária para alcançar a completude. Essa noção de plenitude é reforçada pela ocorrência repetida do círculo como formato motívico.

É importante lembrar que a narrativa da Espanha é produto da escrita de Izzy no Presente e pode-se dizer que

1064 Estudos Feministas, Florianópolis, 21 (3): 1059-1080, setembro-dezembro/2013 
12 "My conquistador, always conquering" (THE FOUNTAIN, 2006). simboliza seus sentimentos. Se mais tarde, na narrativa do Presente, Izzy conclui que não se identifica com as tentativas desesperadas de Tommy de encontrar uma cura, e que talvez aceitar a morte seja uma vitória maior do que curá-la, em seu livro (que se encontra quase concluído quando a narrativa do Presente inicia), seu doppelgänger, Isabel não quer morrer e encara sua salvação como responsabilidade de seu cavaleiro leal, que ela recompensará com sua sexualidade (e, de fato, Izzy chama Tommy, no Presente, de "meu conquistador, sempre conquistando" ${ }^{12}$ ). Apesar de Isabel, diferentemente de lzzy, não aceitar a morte, ela é contra matar o inquisidor (o que significaria curar o câncer) e crê na possibilidade de "viver para sempre", que é prometida pela junção do homem e da mulher. Em sua tentativa de universalizar essa possibilidade, o filme expõe como a diferença de gênero, que é essencial para a dimensão sacralizada da união heterossexual, está entrelaçada profundamente com a lógica colonialista.

\section{Gênero e exploração animal na narrativa do Presente}

As práticas coloniais exibidas na Espanha quinhentista reemergem no Presente contra outro Outro-o corpo animal. É interessante ressaltar que o ponto de vista colonial é introjetado na narrativa do Presente por meio de vários mecanismos, como se designasse a América do Norte do Presente para herdeira do discurso de dominação colonial. O principal desses mecanismos é a inscrição de toda a narrativa Espanhola dentro do presente na forma do livro que lzzy está escrevendo, mas esse não é o único mecanismo utilizado: logo após o clímax da primeira cena no Presente, vemos uma tomada de ruínas maias e somos convencidos de que o filme nos levará de volta para a narrativa da Espanha. No entanto, a câmera se afasta para revelar que as ruínas não são nada além de um quadro emoldurado na parede da casa de Tommy e lzzy, e que ainda estamos seguindo Tommy depois que ele saiu do trabalho. Outro traço interessante é o fato de que a casa do casal é mobiliada principalmente com móveis escuros de madeira, que, juntamente à baixa iluminação e amplas portas e janelas, transmite uma aparência austera e espanholizada reminiscente da narrativa do passado. Assim como a decoração sublinha a assimilação do ponto de vista do colonizador espanhol, o quadro emoldurado reinsere a América Central como o Outro colonizado, agora domesticado.

É importante observar que lzzy como protagonista, e não como a sua criação Isabel, aparece pela primeira vez no filme após a marca dos 20 minutos. Apesar de ela, juntamente com Tommy, estar no centro do conflito de gênero do filme, fica claro que ela ocupa uma posição passiva dentro 
${ }^{13}$ Cary WOLFE e Jonathan ELMER, 2003 , p. 104-105, tradução minha.

14 Karen WARREN, 1996, p. xiii, tradução minha.

${ }^{15}$ WARREN, 1996, p. xii, tradução minha.

${ }^{16}$ Maneesha DECKHA, 2008, p. 251.

${ }_{17}$ DECKHA, 2008, p. 252. de um modelo narrativo binário, dividido entre agente $e$ paciente. É ela quem está doente e quem precisa lidar com a iminência da morte, mas somos interpelados pelo filme a habitar a posição de sujeito de Tommy, à medida que ele pensa em novas maneiras de lidar com o corpo de lzzy como um objeto para ser protegido e salvo. Essa territorialização do corpo dela em nome de seu bem-estar, além de ecoar a lógica colonial de invasão pelo bem das mulheres, é produzida por meio de uma territorialização semelhante à dos corpos de animais.

As forças semelhantes de corporificação e objetificação que afetam mulheres e animais já foram sublinhadas por feministas e pós-humanistas e são de especial importância para o que tem se chamado de ecofeminismo. Carol J. Adams explorou, em seu livro The sexual politics of meat: a feminist-vegetarian critical theory, "como a instituição do especismo [...] articula os corpos comestíveis dos animais e os corpos sexualizados das mulheres, inscrevendo ambos no que Karen Warren chama de uma 'lógica de dominação' comum". ${ }^{13}$ A própria Warren, por sua vez, sublinha o fato de que muitas feministas consideram que "a pecuária, a experimentação animal, a caça e o carnivorismo [meat-eating] estão ligados a práticas e conceitos patriarcais"14 e que tal uso dos animais reproduz e depende da lógica intrinsecamente dialética de dualismos como "razão/emoção, mente/corpo, cultura/natureza, humano/ natureza, homem/mulher". ${ }^{15}$ A "lógica de dominação" conceitualizada por Warren, que sustenta dicotomias que se reforçam mutuamente, não apenas alimenta o discurso do colonialismo, mas também o discurso da exploração e dominação científicas.

Maneesha Dechka explora, em seus escritos, a maneira como a ciência, aliada aos interesses coloniais, foi capaz de produzir a diferença de espécie a partir das marcas de raça e gênero, e vice-versa. Ela aponta de que forma as teorias darwinistas de continuísmo biológico entre humanos e animais criaram uma ansiedade humanista que foi então aliviada pela tradução do darwinismo para a dimensão social. ${ }^{16}$ A ascensão à civilização era vista como o telos do animal humano propriamente evoluído, enquanto os Outros raciais, culturais e de gênero eram vistos como menos humanos na sua distância da civilidade e, portanto, mais animales$\mathrm{cos}^{17}$ Ao interpor esse Outro entre si mesmos e os animais, os colonizadores brancos puderam se esquivar da ansiedade humanista e criar uma ciência a partir da lógica dualista da dominação. Por sua vez, essa ciência foi responsável por um novo tipo de colonização - baseada na exploração e redescrição "científicas" - dos corpos femininos e de animais nos séculos XIX e XX. 
Apesar da observação de que mulheres e animais são sujeitos à 'mesma estrutura geral de 'outrização' [othering]", para usar uma frase de Wolfe e Elmer, demonstrarse uma conclusão válida, deve-se ressaltar que o filme nos pede para considerarmos que o corpo de lzzy é objetificado de formas totalmente diferentes da exploração do corpo de Donovan, o macaco em que Tommy está fazendo experimentos. $E$ é interessante que o filme adie o momento em que revela que Tommy pesquisa tumores cerebrais em macacos por vários minutos. Uma vez que, ao início da narrativa do Presente, ainda não sabemos que lzzy tem um tumor cerebral, só podemos concluir que a reação frustrada de Tommy ao saber do fracasso do experimento inicial se deve à sua incapcidade de ajudar seu paciente. Apesar de não podermos ver Donovan em nenhum momento, a atmosfera de suspense da cena é totalmente canalizada para sua situação delicada de vida e morte.

Embora a palavra "eutanásia" tenha sido rapidamente mencionada, não temos motivo para acreditar que Donovan não é humano, e seguimos Tommy até outra sala, onde ele joga suas luvas no chão e se agacha contra a parede, visivelmente nervoso. Segue-se um longo silêncio, durante o qual seus colegas o observam enquanto ele tenta aceitar 0 fracasso, quando subitamente, ao olhar para um círculo de luz na claraboia do teto, Tommy tem uma ideia. Ele sugere que utilizem um composto, o qual haviam experimentado no ano anterior, "daquela árvore da América Central", criando assim a primeira das muitas conexões narrativas entre as diversas tramas.

É curioso notar que a ideia quase milagrosa de Tommy para impedir o crescimento do tumor (e consequentemente a morte de (zzy) se encontra novamente endividada a um pensamento heterossexista. Ele tem sua inspiração ao olhar para o círculo motívico de luz, e sua ideia inclui "uma árvore da América Central", uma descrição que a codifica paralelamente à Árvore da Vida edênica da narrativa anterior. E, ainda, ao explicar para seu colega Antonio como eles podem combinar o composto da árvore com outro, ele lhe instrui a "imaginá-los lado a lado. Entrelaçados um no outro, como dois amantes, a mulher por cima". ${ }^{18}$ Depois Antonio, impressionado, responde: "Eles têm domínios complementa-res!". mide by side. Fold woman on top." (THE FOUNTAIN 2006).

Além do jargão de ficção científica, existe a semente da ideia de que podemos, talvez, resolver o mistério da mortali-dade, se formos capazes de combinar duas partes opostas, mas complementares, homem e mulher.

Somente quando a narrativa retorna à sala de cirurgia, quando eles estão testando o novo composto, é que vemos uma tomada de Donovan e percebemos que se trata de um macaco. Isso cria a sugestão de que a reação exagerada 
19 Jacques DERRIDA apud WOLFE e ELMER, 2003, p. 100, tradução minha.

${ }^{20}$ DERRIDA apud WOLFE e ELMER, 2003 , p. 100 , tradução minha. de Tommy se deveu à sua preocupação com o bem-estar do macaco; no entanto, apenas um minuto depois, Donovan é reinscrito na "lógica da dominação", quando Tommy confessa para sua chefe, Lillian, que ele está lá, na verdade, por causa de Izzy. O ocultamento do macaco e sua seguinte obliteração pela doença de Izzy somente enfatizam as ansiedades que o filme tenta silenciar em relação ao uso dos corpos animais para interesses humanos. Manter o macaco escondido e depois deixá-lo em segundo plano em favor do medo de Tommy de perder sua esposa consiste em um hábil truque que o filme executa para desviar a atenção da exploração que é executada em nome da preservação da conexão quase divina entre homem e mulher. A agitação de Tommy por ter perdido sua aliança de casamento na sala de cirurgia determina que sua frustração ao tentar curar o macaco representa a ameaça de sua união com Izzy; o formato circular do anel sendo novamente um símbolo para a completude da união do homem e a mulher

Portanto, apesar da objetificação similar sofrida por mulheres e animais, a subjetividade que o filme se investe em produzir para lzzy exige que ela se eleve para além de suas conexões com a animalidade. Jacques Derrida aponta de que forma "o sacrifício carnívoro é essencial para a estrutura da subjetividade" e diagnostica a metafísica ocidental como "carnofalogocêntrica," na medida em que ela se define como um sistema no qual a autonomia é "atribuída ao homem (homo e vir) ao invés da mulher, e à mulher ao invés do animal". ${ }^{19}$ O sacrifício animal que ele diagnostica como essencial para os discursos de subjetividade pode ser estabelecido como "um local deixado aberto, na própria estrutura desses discursos (que são também 'culturas') para uma execução não-criminal" do animal. ${ }^{20}$ Esse "local deixado aberto" na produção da subjetividade é exatamente o que o filme se investe em produzir para que a morte de Donovan seja marcada como eticamente aceitável. Uma vez que a proteção da união heterossexual é construída como sendo crucial para a compreensão da própria condição humana, essa união legitima o tratamento coisificante que é dispensado a Donovan.

Assim, o filme entrelaça a questão da diferença de gênero com outra marca de diferenciação - neste caso, o discurso da espécie. Tanto o fato de que a manutenção do casal heterossexual depende da exploração do corpo animal quanto o fato de que a própria objetificação animal só é possível em termos gendrados expressam quão intimamente ligados são os discursos de gênero e de espécie de acordo com a construção do filme; portanto, é importante sublinhar como o filme demonstra as importantes funções que a Teoria Interseccional pode exercer como ferramenta de crítica 
${ }^{21}$ BUTLER apud WOLFE e ELMER, 2003, p. 99, tradução minha.

${ }^{22}$ Cf. Maneesha DECKHA, 2008; $\Theta$ WOLFE e ELMER, 2003.

\footnotetext{
${ }^{23}$ Georges BATAILLE, 1990, p. 9.
}

${ }^{24}$ BATAILLE, 1990, p. 10. textual. Segundo argumenta Judith Butler, "parece crucial resistir ao modelo de poder que colocaria o racismo, a misoginia e a homofobia como relações paralelas ou analógicas, [pois esse modelo] atrasa a importante tarefa de pensar minuciosamente as maneiras em que esses vetores de poder dependem de e empregam uns aos outros para os propósitos de sua própria articulação". ${ }^{21}$

A dimensão constitutiva das intersecções entre diversos discursos de diferença, como os de gênero, classe social, raça e espécie, já foi examinada em outros fóruns. ${ }^{22} \mathrm{Em}$ vez de citar essas análises, espero que minha leitura de A Fonte da Vida possa produzir um efeito argumentativo semelhante em favor da natureza constitutiva dos discursos de diferença, pois, embora lzzy (ou a rainha Isabel) não esteja posicionada na intersecção de múltiplas forças de opressão, os discursos que operam sobre ela - e a incluem como um elemento dependem de seu corpo objetificado, ou de seu status privilegiado, para que se manifestem em outros corpos oprimidos - como as terras colonizadas ou o animal.

\section{Gênero e espécie na política da transcendência}

Pode-se facilmente demonstrar que A Fonte da Vida opera com modos dialéticos (no sentido hegeliano) de compreender a morte e a humanidade, da mesma forma com que lida com o binarismo dialético entre masculino e feminino. O pensamento de Hegel talvez tenha sido mais profundamente explorado pelas conferências de Alexandre Kojève nos anos de 1930, nas quais se tentou analisar a obra hegeliana sob a luz dos novos paradigmas filosóficos do século XX - sendo o pensamento de Heidegger um deles. ${ }^{23}$ Porém, essas conferências só foram publicadas nos anos de 1940, com base em anotações de seus alunos. Esse fato aponta para a importância da recepção de Kojève para a compreensão de sua análise de Hegel. Georges Bataille foi um de seus alunos assíduos, e seus escritos sobre Kojève mostram-se muito produtivos para uma leitura da metafísica hegeloheideggeriana da morte em A Fonte da Vida e de suas conexões inevitáveis com os discursos de gênero e de espécie.

O princípio central da dialética hegeliana é a negação, através da qual uma tese pode negar sua antítese e, assim, adquirir sua identidade ou reconhecimento. A História é, segundo Hegel, produto da Ação humana, que nada mais é do que a sequência paciente de atos consecutivos de negação. ${ }^{24}$ A Negatividade, portanto, surge como o conceito definitivo da dialética, que a acionará para produzir tanto o humano quanto a sua História. A primeira Ação negativa na produção do humano é a negação da 
${ }^{25}$ Giorgio, AGAMBEN, 2004, p. 12 , tradução minha.

${ }^{26}$ BATAILLE, 1990, p. 12, tradução minha.

27 Martin HEIDEGGER citado por AGAMBEN, 2006, p. 9.

${ }^{28}$ AGAMBEN, 2006, p. 14.

${ }^{29}$ BATAILLE, 1990, p. 15, tradução minha.
Natureza e de sua origem animal. O humano pode realmente ser humano, em termos hegelianos, "somente na medida em que ele transcende e transforma o animal antropóforo que o sustenta, e somente porque, através da ação da negação, ele é capaz de dominar e, por fim, destruir sua animalidade". ${ }^{25}$

Para Hegel, essa negatividade, que é tão crucial para a própria humanidade dos seres humanos, encontra na morte sua principal expressão: "se o animal que constitui o ser natural do homem não morresse, e [...] se a morte não habitasse nele como fonte de sua angústia, [...] não haveria nem homem, nem liberdade, nem história, nem indivíduo." ${ }^{26}$ Isso quer dizer que o ser humano linguístico e dialético depende de sua relação com a morte, uma vez que ela é a principal manifestação da Negatividade que possibilita aos humanos superarem a natureza e a animalidade. Esse laço inquebrável entre o vínculo humano com a morte e a relação negativa do humano com a animalidade é precisamente o que defendo estar em jogo na narrativa de A Fonte da Vida e que se mostra profundamente heideggeriano em sua formulação.

De acordo com Heidegger, "os mortais são aqueles que podem ter a experiência da morte como morte. O animal não o pode, mas o animal tampouco pode falar. A relação essencial entre morte e linguagem surge como num relâmpago, mas permanece impensada." 27 Vê-se também na filosofia de Heidegger a ligação (hegeliana) entre humanidade e morte, na medida em que o Dasein - o modo de ser supostamente característico do ser humano - somente pode se produzir através da negatividade que lhe está disponível na sua relação com a morte. É somente em sua contemplação do Nada que existiria do outro lado da morte que o humano pode ascender à sua natureza dialética definitiva do autorreconhecimento..$^{28} \mathrm{O}$ papel crucial da morte como a fonte da Negatividade que possibilitará a divisão da Natureza em elementos (e a separação do humano de seu corpo animal) já sugere a diferença, tão relevante para o filme, entre imanência (a Totalidade da Natureza) e transcendência (e relação humana com a morte).

Na imanência não pode haver "um puro eu abstrato o qual é essencialmente oposto à fusão", ${ }^{29}$ e a morte não se encontra indefinidamente adiada para estar disponível em sua inacessibilidade. A morte é inscrita na Totalidade da imanência, como supostamente seria o caso dos animais. Conforme defendido por Heidegger, um animal não pode experienciar sua individualidade, pois não possui a Compreensão necessária para isolar os elementos da Totalidade. E nessa compreensão se encontra a possibilidade da morte:

Para se separar das outras, uma mosca precisaria da força monstruosa da compreensão [entendement]; e assim ela se nomearia e faria o que a compreensão 
${ }^{30}$ BATAILLE, 1990, p. 15, tradução minha.

${ }^{31}$ BATAILLE, 1990, p. 18.

32 "I feel different, inside. [...] Every moment. Each one." (THE FOUNTAIN, 2006, tradução minha). possibilita por meio da linguagem, que é a única capaz de inaugurar a separação dos elementos, [...] um mundo formado por entidades separadas $e$ denominadas. Mas nesse jogo o animal humano encontra a morte. ${ }^{30}$

Esse modelo de subjetividade dialética é o que vemos em funcionamento na caracterização de Tommy em $A$ Fonte da Vida. Ele fica fascinado pela morte corporificada em lzzy, na medida em que essa morte possibilita a própria Negatividade que aciona seu autorreconhecimento. Somente por ele ver a si mesmo, Izzy e a união entre eles como "distinto[s] e insubstituíve[is]" - uma conclusão que somente a morte possibilita - é que ele teme tanto a ideia do desaparecimento inerente no morrer ou na morte de lzzy. O repúdio estratégico da morte animal por parte do filme e de Tommy é, portanto, totalmente compreensível em vista de sua função de possibilitar a construção dialética da individualidade humana por meio da Negação do animal. O sacrifício que Derrida sublinha estar no cerne da subjetividade é o mesmo sacrifício animal que Bataille identifica como a maneira do ser humano atualizar a morte, liberando assim sua Negatividade, que é capaz de criar a humanidade a partir da animalidade. ${ }^{31}$

Dessa forma, é importante para Tommy manter a morte distante para marcá-la como inacessível e o seu relacionamento com o mundo como transcendental, pois só pode haver transcendência se uma dimensão externa for mantida inacessível. Por essa razão, é crucial que a caracterização de Izzy no filme seja constantemente reforçada como imanente. O primeiro exemplo de sua relação imanente com a morte é a primeira cena da narrativa do Presente descrita acima, na qual ela se funde com a luz vinda do lado de fora, mas essa relação é, também, continuadamente reinscrita na insistência de lzzy de discutir a morte e procurar aceitá-la, diferentemente de Tommy, que se irrita com o misticismo imanente da esposa, e de suas tentativas desesperadas de reverter a morte para manter a relação deles transcendental.

Gradualmente, o medo de Izzy da morte (visível no desejo de sua personagem Isabel pela imortalidade) tornase aceitação. Quando Tommy descobre que ela anda perdendo a "sensibilidade ao calor e ao frio", um sintoma da progressão da doença, ele fica alarmado e deseja ligar para o médico, mas ela lhe explica que "se sente diferente, por dentro. [...] Em todos os momentos. Cada um deles." ${ }^{32} \mathrm{O}$ que o filme apresenta como seu arco narrativo é a conversão gradual de Tommy para os valores que lzzy está aprendendo em sua nova relação com a morte. Também é interessante que seja possível identificar a distribuição das marcas de gênero também na teoria dialética de Hegel. 
${ }^{33}$ BATAILLE, 1990, p. 16, tradução minha.

${ }^{34}$ BATAILLE, 1990, p. 16, tradução minha.

${ }^{35}$ BATAILLE, 1990, p. 16, tradução minha.
Hegel opõe a Compreensão do Homem (sic) à "beleza pura do sonho, que não é capaz de agir, que é impotente". ${ }^{33}$ A beleza é equacionada à imanência, uma vez que ela "se encontra no lado do mundo onde nada está ainda separado de seus arredores". ${ }^{34}$ A linguagem de Hegel (assim como a de Kojève e a de Bataille), que opõe as palavras "Homem" e "beleza", sugere que a transcendência (juntamente com a Compreensão e a Negatividade), estando oposta à imanência, reproduza uma lógica de gênero que consiste de um sujeito masculino e de um objeto feminino. "A beleza não é capaz de agir [...] Através da ação ela não mais existiria, uma vez que a ação destruiria antes de tudo o que a beleza é: a beleza, que não busca nada, que é, que se recusa a se mover mas que é perturbada pela força da Compreensão." 35

A sugestão hegeliana de Compreensão masculina e beleza feminina descreve perfeitamente como as representações cinemáticas marcam Tommy e lzzy, respectivamente, como transcendente e imanente, e como essas caracterizações são gendradas. Conforme mencionado anteriormente, Izzy como personagem age muito pouco e opera mais como receptora das ações de Tommy. A missão da busca pela sua cura é adotada somente por Tommy, e as convenções fílmicas de iluminação e enquadramento estabelecem Tommy como o centro de identificação narrativa e lzzy como foco de objetificação escopofílica. Isso é claramente demonstrado em uma cena na qual, acompanhado da câmera, Tommy sobe as escadas do museu onde ele deve encontrar lzzy, para no patamar e se vira procurando-a. No chão imediatamente atrás dele, há um amplo e destacado círculo de luz sobre o qual ele não pisa. Ele caminha até o limiar do halo de luz e sai andando pelo lado esquerdo do quadro, procurando por lzzy. Izzy então mostra para Tommy um livro maia que representa o mito da criação, e quando ela narra como o Primeiro Pai se sacrificou para criar o mundo, Tommy só demonstra aversão. Izzy insiste na noção da "morte como um ato de criação", mas Tommy muda de assunto e, ao se afastar dela para ir buscar o carro, vemos uma tomada subjetiva, do ponto de vista de Tommy, enquadrando Izzy fitando-o com uma expressão vulnerável. Cambaleando, ela dá um passo para trás e se posiciona debaixo de um forte círculo de luz branca que a envolve de cima e satura sua imagem de branco. Ela olha para a luz acima, revirando os olhos, e desmaia, não antes de um plano aberto enquadrar Tommy correndo em câmera lenta para ampará-la. A imanência dela é novamente sublinhada pela forma com que seu corpo, coberto de bran$\mathrm{co}$, parece se fundir com a luz, enquanto Tommy, normalmente de preto e filmado nas sombras, contrasta fortemente com essa brancura. 
36 "All flesh decays, death turns all to ash, and thus death frees every soul." (THE FOUNTAIN, 2006, tradução minha).

${ }^{37}$ BATAILLE, 1990, p. 10.

${ }^{38}$ BATAILLE, 1990, p. 12, tradução minha.
A imanência de lzzy, porém, não é análoga à imanência do animal que, segundo Hegel e Heidegger, não é capaz de ter uma relação com a morte. No tratamento específico da imanência de lzzy, pode-se identificar como o discurso de espécie opera dentro das formulações metafísicas do serpara-a-morte excepcional do ser humano. O que importa para lzzy, em sua reinscrição da morte em uma relação imanente, é a busca por um sentido para a vida, o qual somente uma morte "transcendental" pode trazer. Neste ponto é relevante esclarecer a paradoxal "transcendência na imanência" que ela procura, pois é precisamente isso que diferencia os tipos de morte (e de vida) que estão disponíveis para ela e para Donovan.

É produtivo revisitar a narrativa da Espanha para sublinhar como o filme codifica a diferença entre transcendência e transcendência na imanência: o que está em jogo na guerra entre "cruz e coroa" se trata claramente de uma política da transcendência. O inquisidor teme a aniquilação da mortalidade que um elixir da vida eterna promete e o papel obsoleto da lgreja em um mundo onde as pessoas possam encontrar transcendência em vida - segundo ele mesmo pronuncia ao som dos soluços dos hereges: "Toda carne perece, a morte transforma tudo em cinza, e assim a morte liberta toda alma." 36

No discurso do inquisidor, temos o modelo da transcendência ocidental clássica, na qual uma relação vertical para com uma dimensão posta fora do alcance (nesse caso, Deus e o Paraíso) é a fonte de sentido para uma vida que se quer transcendental, como a humana. Da mesma forma que Kojève diagnostica a filosofia hegeliana como uma filosofia do ateísmo, ${ }^{37}$ para os protagonistas de A Fonte da Vida, que vivem em um mundo posterior à "morte de Deus" nietzschiana, não se pode contar com a transcendência na forma de uma divindade ou de uma vida após a morte. É justamente por isso que há tanta ênfase na desconcertante alteridade da morte em filosofias ateias como a de Hegel e a de Heidegger, pois a inacessibilidade da morte resta como garantia única da natureza transcendental do ser humano. Segundo a formulação de Bataille, "para o mundo judaico-cristão, a 'espiritualidade' só é realizada e manifesta em sua totalidade no além-vida. [...] Isso quer dizer que somente a morte garante a existência de um ser 'espiritual' ou 'dialético', no sentido hegeliano."38

A gradual aproximação de lzzy ao limiar da morte impede que ela utilize sua mortalidade para estabelecer sua natureza transcendental. Ela não pode, porém, morrer como um animal, ou seja, sem ciência da morte e sem pesar pela perda da vida, senão ela colocaria em risco o discurso de espécie que estabelece os humanos como sagrados, ou anularia o sacrifício animal que Hegel afirma inaugurar a humanidade. Sua tentativa de encontrar "transcendência 
${ }^{39}$ LUC FERRY, 2008.

${ }^{40}$ FERRY, 2008

${ }^{41}$ FERRY, 2008.

42 "I wasn't afraid. [...] When I fell, I was full. Held." (THE FOUNTAIN, 2006, tradução minha).

43 "I know, I caught you, I held you!" (THE FOUNTAIN, 2006, tradução minha). na imanência" pode ser compreendida melhor quando alinhada com formulações filosóficas que tentam dar conta do Zeitgeist do individualismo tardo-capitalista, no qual não há espaço para a transcendência tradicional.

O filósofo pop francês Luc Ferry, cujos livros têm títulos e vendas que poderiam incluí-lo na seção de autoajuda, oferece um dos melhores diagnósticos da espiritualidade burguesa tardo-capitalista, junto com um modelo filosófico que se aplica a esse fenômeno. Ele argumenta que a vida humana (e principalmente a vida das pessoas que amamos) é a última coisa sagrada que resta na sociedade ocidental. Os valores pelos quais as pessoas morriam no passado, diz ele, como Deus e a Nação, não incitam mais a sensação do sagrado nas pessoas e não são capazes de dar sentido às suas vidas. Segundo Ferry, "o sagrado não desapareceu, ele só mudou de lugar e se encarnou na humanidade. Passamos da transcendência vertical - Deus, pátria, as grandes utopias - para a transcendência horizontal - os homens." 39 Formulada dessa forma, sua filosofia é bastante conveniente para um momento histórico de Estados gerenciais e biopolítica, no qual o Estado toma para si a tarefa de cuidar da vida biológica de sua população, seu bem mais valioso. Na pós-modernidade globalizada, seguindo a mesma lógica, os valores da classe média que surgiram com o nascimento do capitalismo e da família nuclear se tornam o foco das políticas estatais, no lugar da expansão e manutenção da nação. Como Ferry mesmo diagnostica, "no Ocidente, [...] a política, em vez de ser um fim em si mesma, [é] um auxílio para a vida privada." 40 Esse panorama cultural, filosófico e político é exatamente o que lzzy e Tommy habitam, e a tentativa dela de dar sentido para seus últimos dias é a resposta de uma mulher pósmoderna à morte, em um mundo sem a transcendência de Deus ou uma causa ideológica pela qual morrer. Exatamente porque a morte hegelo-heideggeriana não funciona para a transcendência dela como para Tommy, ela precisa encontrar uma forma de incorporar a morte em sua "Totalidade" - ela precisa, em outras palavras, encontrar o absoluto na imanência. Para Ferry, "antigamente, o valor absoluto era uma coisa transcendente, ou seja, superior a nós, como Deus e a eternidade. O valor absoluto caía do céu. Mas agora ele está em nós, o que eu chamo de uma 'transcendência na imanência'."41

Pode-se identificar em lzzy esse tipo de transcendência na imanência na forma em que ela gradualmente tem uma sensação sacra ao aceitar a morte. Ao acordar no hospital após desmaiar no museu, ela informa a Tommy que "não estava com medo. [...] Quando eu caí, eu estava plena. Segura [held]", ${ }^{42}$ e ele responde: "Eu sei, eu peguei você, eu segurei você [held you]!", ${ }^{43}$ incapaz de entender que não são as tentativas dele de curá-la que a fazem se sentir mais humana. 
44 "He said his father became part of that tree. He grew into the wood, into the bloom. And when a sparrow ate the tree's fruits, his father flew with the birds. He said death was his father's road to awe." (THE FOUNTAIN, 2006, tradução minha).

${ }^{45}$ BATAILLE, 1990 , p. 20 , tradução minha.
O livro de lzzy também é um dos meios através dos quais ela tenta encontrar esse tipo de transcendência. Ao inscrever seu próprio conflito com a mortalidade na história da rainha Isabel, ela cria a ficção de que precisa para dar sentido à sua vida (e à sua morte). Ela explica para Tommy que o livro começa na Espanha, mas termina em Xibalba, a estrela que os maias acreditam abrigar o além-vida, onde as almas iriam para renascer; porém, no mundo norte-americano sem mitos do século XXI, mitos maias não passam de curiosidades, e Izzy precisa encontrar sua transcendência maia de outro modo. Relutantemente, Tommy a ouve explicitar sua crença em uma possível vida após a morte: ela reconta a história que ouviu sobre o pai do seu guia turístico maia, que morrera e que "continuara a viver" na árvore que foi plantada sobre seu túmulo. "Ele disse que seu pai tornou-se parte da árvore," diz lzzy. "Ele cresceu na madeira, na florada. E quando um pardal comeu os frutos da árvore, seu pai voou com os pássaros. Ele disse que a morte foi para o seu pai o caminho para o sublime [road to awe]." 44

O uso da ficção por parte de lzzy, tanto sob a forma de seu livro quanto no modo em que ela costura pedaços de mitos maias, também é explorado por Bataille como um elemento crucial da relação humana com a morte. Precisamente porque a morte só ocorre quando morremos, é importante que os seres humanos se tornem cientes em vida da negatividade da morte, para que seu potencial criativo para a Ação possa ser desencadeado. É por esse motivo que, para Bataille, o sacrifício e o espetáculo da morte são necessários para a sua compreensão pelos humanos. Sem esse tipo de representação, argumenta Bataille, "seria possível para nós continuarmos alheios e ignorantes em relação à morte, assim como as bestas aparentemente são. E de fato, nada é menos animal do que a ficção, que é mais ou menos separada do real, da morte." ${ }^{45}$ Por meio de uma reconfiguração da morte em seu livro, lzzy deixa claro que sua imanência nunca fora análoga à imanência do animal e que o discurso da espécie é um componente fundamental para as filosofias metafísicas da morte e da mortalidade. Mas o mesmo se aplica ao discurso de gênero, como o conflito central do filme revela.

Tendo determinado o tipo de imanência transcendental que Izzy está buscando, podemos dizer que o tema do filme é a gradual aceitação, por Tommy, de sua postura feminina perante a possibilidade da imanência. O elemento de gênero reemerge quando Izzy presenteia Tommy com uma caneta-tinteiro para que ele termine o livro para ela. Se o livro representa a ficção que possibilita a transcendência sobre o animal, Izzy precisa da ligação homem-mulher para realmente alcançá-la. Além disso, podemos ler sua dependência em Tommy para finalizar o livro como uma marca da ineficácia 
46 "We struggle all our lives to become whole, complete enough when we die, to achieve a measure of grace. Few of us ever do. Most of us end up going out the way we came in: kicking and screaming. But somehow Izzy, young as she was, she achieved that grace. In her last days she became whole." (ARONOFSKY, 2006, tradução minha). da escrita feminina. A ficção de uma mulher, o filme aparentemente nos diz, só pode levá-los até certo ponto. Depois disso é imperativo que Tommy seja convertido ao sistema de crenças de lzzy para concluir a criação ficcional de seu modo especialmente humano de morrer. Assim, a palavra "terminar" [finish] torna-se um tipo de motivo verbal juntamente ao círculo como motivo visual. E, se ele afirma não saber como termina a história, ela declara firmemente que ele saberá.

Devido a uma coincidência infeliz, Tommy descobre, segundos antes de lzzy morrer de uma parada cardíaca, que o composto retirado da árvore da América Central começou a diminuir o tumor de Donovan. A partir desse ponto, o que está em jogo para Tommy é saber como "terminar" a ficção deles, como alcançar o absoluto ao lado de lzzy segundo ela lhe instruiu. Ele parece sentir que deve tomar o caminho imanente-transcendental da aceitação da morte, mesmo que indicado apenas por seu desespero em não encontrar sua aliança de casamento. A ponta da caneta-tinteiro dada por lzzy se torna mais uma das obsessões visuais do filme, como forma do dispositivo fálico que lhe entregará o poder de escrita para concluir sua ficção de união sagrada, o que lzzy foi incapaz de fazer com sua escrita feminina. O contraste visual entre as formas da caneta (fálica) e do círculo (feminino) sugere o conflito interno de Tommy e alcança um clímax quando ele, perturbado por não ter encontrado sua aliança de casamento, tatua um anel no dedo usando a caneta e a tinta que lzzy lhe deu.

Nesse ponto a resolução do conflito está clara: Tommy só encontrará a absoluta transcendência em sua imanência com lzzy quando ele ceder ao que os círculos representam: a aceitação feminina da morte. Apesar de o filme antecipar visualmente sua conversão, ele ainda demora para aceitála. No enterro de lzzy, Tommy reage agressivamente ao ouvir o elogio de Lilian, que referencia positivamente a política da imanência transcendental. Ela defende, enquanto Tommy balança a cabeça em desaprovação, que

batalhamos a vida toda para ficarmos plenos, completos o bastante quando morremos, para alcançar uma certa medida de graça. Poucos de nós conseguem. A maioria se vai assim como viemos: esperneando e gritando. Mas de alguma forma, lzzy, apesar de jovem, atingiu essa graça. Em seus últimos dias, ela se tornou plena. ${ }^{46}$

Não obstante o repúdio especista da origem mamífera do humano (no parto), o tributo de Lilian soa para Tommy como uma renúncia desnecessária da condição humana especial. Ele se afasta do enterro durante o discurso dela e diz que acredita que "a morte é a uma doença" para a qual ele encontrará a cura. Baseando-se nas pistas deixadas por 
${ }^{47}$ É Claro que esquematizada acima está apenas a minha interpretação do que realmente está acontecendo na narrativa do Espaço, e existem outras leituras possibilitadas pelo filme, principalmente devido à característica elíptica dessa terceira trama. Acredito, porém, que esse arranjo dos elementos é o que melhor explica as questões deixadas em aberto no decorrer do filme.

48 "Together we will live forever." (THE FOUNTAIN, 2006, tradução e ênfase minhas).
Izzy, ele acredita estar realizando o desejo dela ao plantar uma árvore sobre seu túmulo e, com a ajuda do composto misterioso da árvore da América Central, combater os efeitos do envelhecimento para sobreviver até um futuro distante, quando ele enfim extrai a árvore e a coloca dentro da esfera transparente que vemos na narrativa do Espaço, na qual ele pretende voar em direção a Xibalba. ${ }^{47}$

Vemos mais uma vez o conflito entre a caneta e o círculo quando Tommy tatua mais um em uma série de "anéis" em seu braço, os quais ele acrescentou à tatuagem da aliança através dos anos. De certa forma, pode-se ler toda a narrativa do Espaço como a marca da compreensão equivocada das crenças de Izzy por Tommy. A hiperbólica viagem espacial em que ele se lança como mais uma das formas de expansão e conquista (que é, assim, adicionada e articulada à invasão da América Central e à exploração dos corpos dos macacos) parece ser a tentativa masculinista, logocêntrica e tecnofílica de entender o que lzzy quis dizer quando afirmava que a morte é o caminho para o sublime [awe].

À medida que a árvore exibe sinais de que está morrendo antes de a esfera chegar até a estrela, Tommy se desespera. Nesse momento, tanto Izzy quanto a rainha Isabel aparecem dentro da esfera e insistem para que Tommy "termine" [finish it]. Finalmente o rosto de Tommy é inundado por luz branca, e ele afirma jubiloso: "eu vou morrer!" [l'm gonna die!], ao que Izzy responde, "juntos viveremos para sempre". ${ }^{48}$

Nesse momento climático, no qual Tommy está prestes a aceitar a morte, causada por uma explosão estelar, o filme nos traz de volta para o drama doméstico da primeira cena da narrativa do Presente, em que eles discutiam sobre administração do tempo. A cena se repete, mas dessa vez ele a segue e sai pelas portas duplas em direção à paisagem nevada e ensolarada. Com essa manobra discursiva, o filme valida sua preocupação com mortalidade e transcendência como nada mais do que uma alegoria do melodrama do casal que tenta acomodar a diferença de gênero dentro da vida cotidiana de uma relação heterossexual. As cenas que se seguem funcionam apenas para concluir essa linha de raciocínio, uma vez que trabalham com uma imagética sexual e orgásmica.

O filme simultaneamente arremata as narrativas da Espanha e do Espaço, porquanto Tomás encontra a Árvore da Vida escondida na pirâmide maia, e Tommy, do Espaço, alcança a estrela moribunda. Tomás penetra a árvore com uma adaga fálica e bebe a seiva apenas para "morrer de vida", quando flores brotam de sua ferida e de sua boca. Enquanto Tommy, no Espaço, está se preparando para a explosão da estrela, o anel que Isabel deu a Tomás aparece para ele, e, à medida que a música apoteótica explode, ele veste o anel. A estrela explode, disseminando partículas de luz e 
fazendo com que a árvore no interior da esfera floresça. A última cena nos mostra o momento contemplativo em que Tommy plantou a semente sobre o túmulo de lzzy (sendo a semente, num momento marcado por uma iluminação irreal e "metafórica", apanhada por lzzy e entregue na mão de Tommy).

O filme conclui, assim, com uma sequência de imagens de clímax sexual e de inseminação procriativa masculina, como se representasse a tradução final da potencialidade da união do homem e da mulher de significar a possível transcendência humana sobre a animalidade nos tempos modernos. O deslocamento do foco de inseminação feminina para masculina (como é sucintamente exibido na última cena) codifica a forma com que o filme, ao mesmo tempo em que exige que Tommy adquira uma postura "feminina", centra suas preocupações humanistas na subjetividade masculina. Esse deslocamento - ao formar um sistema com os deslocamentos animal-humano, colônia-colonizador, mundo-Espaço - revela o caráter interseccional dos discursos empregados pelo filme.

Espero ter demonstrado de que maneira A Fonte da Vida, em sua tentativa de validar seu conflito principal gendrado, expõe a forma pela qual discursos de diferença de gênero acabam por produzir e depender de outros discursos opressivos, como especismo, colonialismo, racismo e heterossexismo. Além disso, o largo âmbito temporal do filme ajuda a demonstrar que essas formas de opressão - muito além de serem antigas - são de fato reforçadas por suas contínuas interrelações retroativas. Finalmente, acredito que minha análise exibe o potencial da Teoria Interseccional de possibilitar uma leitura filosófica cruzada através de diversas ferramentas de crítica textual, uma vez que oferece a possibilidade de identificar como as ideologias de diferenças se constituem e se reforçam mutuamente.

\section{Referências}

AGAMBEN, Giorgio. The Open: Man and Animal. 2002. Tradução de Kevin Attel. Stanford: Stanford University Press, 2004.

A Linguagem e a Morte. 1985. Tradução de Henrique Burigo. Belo Horizonte: UFMG, 2006.

BATAILLE, Georges. "Hegel, Death and Sacrifice". 1955. Tradução de Jonathan Strauss. Yale French Studies, v. 78, p. 9-28, 1990.

BROWN, Paul. "This Thing of Darkness I Acknowledge Mine: The Tempest and the Discourse of Colonialism." In: SHAKESPEARE, William. The Tempest: a case study in critical controversy. London: Palgrave Macmillan, 2000, p. 205-229.

CALARCO, Matthew. "Heidegger's Zoontology." In: ATTERTON, Peter. (Orgs.). Animal Philosophy: Essential 
Reading in Continental Thought. London; New York: Continuum, 2004, p. 18-30.

DECKHA, Maneesha. "Intersectionality and Posthumanist Visions of Equality." Wisconsin Journal of Law, Gender \& Society, v. 23, n. 2, p. 249-267, 2008.

FERRY, Luc. Entrevista com Luc Ferry. Superinteressante. Abril.com, 22 abr. 2008. Disponível em: <http:// super.abril.com.br/cotidiano/entrevista-luc-ferry447617.shtml >. Acesso em: 10 jul. 2012.

GRILLO, Trina. "Anti-Essentialism and Intersectionality: Tools to Dismantle the Master's House". Berkeley's Women Law Journal, v. 10, p. 16-30, 1995.

KAPLAN, Ann. Looking for the Other: Feminism, Film, and the Imperial Gaze. New York: Routledge, 1997.

LAURETIS, Teresa de. "A tecnologia do gênero." In: HOLLANDA, Heloísa Buarque de (Org.). Tendências e impasses: o feminismo como crítica da cultura. Rio de Janeiro: Rocco, 1994, p. 206-242.

LOOMBA, Ania. "Gender, race, Renaissance Drama." In: SHAKESPEARE, William. The Tempest: a case study in critical controversy. London: Palgrave Macmillan, 2000, p. 324-335.

MULVEY, Laura. "Prazer Visual e Cinema Narrativo". In: XAVIER, Ismail (Org.). A Experiência do Cinema: antologia. Rio de Janeiro: Graal, 1983, p. 437-454.

THE FOUNTAIN. Direção de Darren Aronofsky. Regency, 2006. 1 DVD.

WARREN, Karen. "Ecological Feminist Philosophies: An Overview of the Issues." In: (Org.). Ecological Feminist Philosophies. Bloomington: Indiana University, 1996, p. ix-xxvi.

WOLFE, Cary; ELMER, Jonathan. "Subject to Sacrifice: Ideology, Psychoanalysis, and the Discourse of Species in Jonathan Demme's The Silence of the Lambs." In: WOLFE, Cary. Animal Rites: American Culture, the Discourse of Species, and Posthumanist Theory. Chicago and London: University of Chicago, 2003, p. 97-121.

WOLFE, Cary. "Fathers, Lovers, and Friend Killers: Rearticulating Gender and Race via Species in Hemingway." Boundary 2, v. 29, n. 1, p. 223-257, 2002.

[Recebido em 11 de setembro de 2012 , reapresentado em 26 de abril de 2013 e aceito para publicação em 20 de junho] 
Vicious Circles: Intersections of Gender and Species in Darren Aronofsky's The Fountain

Abstract: Darren Aronofsky's 2006 film The Fountain presents itself to a productive reading into the ways in which intersectioning discourses of oppression are coded into film and operated on as ideologies. This article will look on the differences of gender, species, and race/ethnicity in the film, and on how they are constitutively articulated in order to enable the "immanence" of the Other in each of these discourses of oppression so as to produce the "transcendental" Subject. I will set out from a philosophical understanding of the essential role of the species difference (and the privilege of the human status) in the intersectional constitution of other vectors of difference, such as gender, sex, race, ethnicity, and ability. I will attempt to articulate this broad form of intersectional approach with a discussion of the supposedly exclusively human relationship with death which allows humanity to be constructed as opposed to animality.

Key Words: Intersectional Theory; Animality; Posthumanism; Film.

1080 Estudos Feministas, Florianópolis, 21 (3): 1059-1080, setembro-dezembro/2013 